\title{
Investigation of train shunt problem in track circuits of signalling and interlocking devices
}

\author{
Adam Razgonov, Anton Zhuravlyov, Kateryna Yashchuk*, and Vadym Shcheka
}

Dnipro National University of Railway Transport named after Academician V. Lazaryan, Department of automation and telecommunications, 49010 Dnipro, Lazaryana Str., 2, Ukraine

\begin{abstract}
The problems of electric track circuits calculating were investigated in the works of various authors, it is noted that there is no complete clarity on the definition of shunt resistance. The value of the calculated train shunt resistance in many respects affects the area of signaling systems rail channel stable operation and train traffic safety. It is relevant to study the possibilities of changing the standard value of and the conditions for the execution of track circuits shunt mode, especially for sections of railway with low resistance insulation of the rail line. The surface area of the "wheel-rail" skating, taking into account the different conditions of interaction dynamics and wear of rails and wheel elements were obtained in article. It is shown that the reduction of the normative value of the resistance of the train shunt is appropriate for signaling systems, especially for sections of railway with low resistance insulation of the rail line. An approximate estimate of the geometric parameters of the membrane that forms on the "wheelrail" surface is obtained; proposed a more complete electrical replacing scheme for the train shunt circuit, which allows analyzing the influence of the circuit elements parameters values and the frequency of the signal current. A method for calculating the correlation dependence of the train shunt resistance from wheel-rail surface membrane parameters is proposed.
\end{abstract}

\section{Introduction}

\subsection{Urgency of the problem and the results of studies of the film on the rail head surface}

Track circuits are road transmitters that determine the location of a mobile unit, which is very important information for train situational awareness in real time. This makes it possible to quickly respond and take appropriate measures both in case of occurred unfavorable train situation and in the very likelihood of its occurrence. When designing new track circuits, as well as analyzing the operation of existing ones, the calculations are made. A prerequisite for the correctness of these calculations takes into account the numerous factors, including shunt resistance $\left(R_{\mathrm{sh}}\right)$. But in this direction some problematic issues concerning the definition of $R_{\mathrm{sh}}$ arise [4-7,10]. This is due to the fact that this parameter depends on a large number of factors acting on it. A characteristic feature is that these factors are independent of each other and are different in their nature. It is difficult, since in order to obtain a complete picture of the physical processes taking place during train movement and to provide a shunt mode, by means of which the location of a mobile unit is determined and which is also subject to mandatory calculation, all factors should be taken into account. At the same time, the stable operation of the rail channel of signaling and interlocking, as well as traffic safety of trains largely depends on the values of the calculated resistance $R_{\text {sh }}$. Hence, it seems relevant to study the possibilities of changing the standard value of $R_{\mathrm{sh}}$ and the conditions for fulfilling the shunt mode of track circuits, especially for the track sections with a reduced resistance of rail line insulation. We will review the publications and some technical solutions on the problem of the train shunt resistance. Researchers from different countries (France, Japan, Germany, etc.) constantly return to this problem. It is noted $[6,7,10]$ that there is no complete clarity on this issue, since the formation of the resistance of rail head contamination occurs under the influence of dynamic, electrochemical processes, temperature, humidity, speed of movement, etc. The shunt resistance also depends on the dynamics of changes in the "wheelrail" contact area in the process of continuous movement of points - A-spots of film break-down at the contact point [11]. The experiments on the measurement of $R_{\text {sh }}(x)$ during the movement of electric train [5] show that in the absence of poor conductive films, the resistance amounts to a few $\mu \mathrm{Ohm}$, despite the fact that $R_{\text {sh }}$ of heavy trains with a shiny rail surface is consistently measured in mOhm.

Also, the work [5] established that the resistance of the "wheel-rail" make-before-break contact nonlinearly depends on the applied voltage (semi-conductor property) and decreases abruptly to a certain critical value determined by the thickness and composition of

Corresponding author: k.i.yaschuk@gmail.com 
the film; the influence of the current frequency from zero to several $\mathrm{kHz}$ on $R_{\mathrm{sh}}$ is insignificant; the influence of the so-called coherent effect is manifested in the time lag in contact establishment, as a result of which the value of $R_{\text {sh }}$ increases with increasing speed. At high speed, the duration of contact is so small that the film between the wheel and the rail does not have time to completely break.

In article [4] the resistance of the "wheel-rail" contact is investigated. The resistance in the frequency range $200-2000 \mathrm{~Hz}$ behaves as an inductive one - its impedance is an increasing function of frequency; $R_{\mathrm{sh}}$ depends on the modes of train movement and increases in the following sequence: stop - braking - thrust coasting retardation. As well, in this paper, the simplified versions of the equivalent circuits for the "wheel-rail" contact are proposed. Below is a more complete version of the equivalent circuit of the train shunt's circuit contact.

Train shunt observations show that non-conductive film on the rails is formed during the trains ' movement and in winter conditions with frosts below $-30 . .-40^{\circ} \mathrm{C}$.

In article [10], the characteristics of a random stationary process (hereinafter $\mathrm{SP}$ ) of changing $R_{\mathrm{sh}}$ of the underground cars are determined. It is established that when moving, $R_{\mathrm{sh}}$ may exceed the norm of $0.06 \mathrm{Ohm}$. Moreover, $R_{\mathrm{sh}}$ of a light mobile unit sometimes reaches several Ohms, which does not ensure proper operation of the track circuits. The $R_{\text {sh }}$ density function well approximated by the $\alpha$-distribution is constructed:

$$
f\left(R_{\mathrm{sh}}\right)=\frac{C_{\mathrm{p}}}{R_{\mathrm{sh}}^{2} \sqrt{2 \pi}} \exp \left[-\frac{1}{2}\left(\frac{\beta}{R_{\mathrm{sh}}}-\alpha\right)^{2}\right],
$$

where the parameters of $\alpha=1.19, \quad \beta=0.184$, $C_{\mathrm{p}}=\int_{R_{\mathrm{sh1}}}^{R_{\mathrm{sh} 2}} f\left(R_{\mathrm{sh}}\right) \cdot \alpha R_{\mathrm{sh}}=1.085 ;$ and the value $\rho=\mu \alpha=$ $=0.103$ from the median $\mu=0.912$.

The SP correlation function approximated by the expression of the form $k(\tau)=A e^{-\alpha_{0} \tau} \cos \left(\omega_{0} \tau\right)$, where $A=1, \alpha_{0}=0.88, \omega_{0}=2.61$ was calculated.

Let us turn to the problem of research [8] on measuring the coefficient of "wheel-rail" adhesion ( $\left.K_{\text {sh }}=0,1 . .0,45\right)$ from the degree of contamination, moistening of the track superstructure, properties and structure of colloidal contaminations of the contacting surfaces - composition, particle size and film thickness.

The results obtained are of interest for explaining some properties of a film on a contaminated rolling surface of "wheel-rail" from the point of view of the interaction physics of chemical, mechanical and electrical processes that affect the film structure and the electrical resistance of train shunt.

The contamination samples were taken in two ways:

1. The rails were coated with a $10 \%$ celluloid solution in acetone, then after 15-20 minutes a film of celluloid was formed on the rail head surface, which was easily removed with contaminations.
2. Contaminations were scraped from the rail head surface with a scalpel.

Scraped films were subjected to photometric measurement in order to determine the thickness of the rail contamination layer (Table 1). After that, the films were dissolved in acetone and the solid particles were separated [8].

Table 1. Film thickness distribution

\begin{tabular}{|c|c|c|c|c|}
\hline \multirow{2}{*}{ Measurements } & \multicolumn{2}{|c|}{ External part } & \multicolumn{2}{c|}{ Tread middle } \\
\cline { 2 - 5 } & $\boldsymbol{h , \mu m}$ & $\boldsymbol{\beta}$, grad & $\boldsymbol{h}, \boldsymbol{\mu m}$ & $\boldsymbol{\beta}$, grad \\
\hline Average value & 33.7 & 83.7 & 7.4 & 47 \\
\hline Dispersion & $4.1-57$ & $16-15$ & $4-11.2$ & $21-93$ \\
\hline
\end{tabular}

Note: $\beta$ is the angle between the horizontal and the tangent to the rolling surface.

The contaminations scraped by the second method were dried and the moisture content was determined.

After benzene washing followed by separation, the powdered contaminations were directed to a microscope survey and to X-ray, chemical and spectral analyses. Microscope survey showed that the contaminations are powders with particles of indeterminate forms. The statistical curve of particle size distribution [8] is shown in Fig. 1.

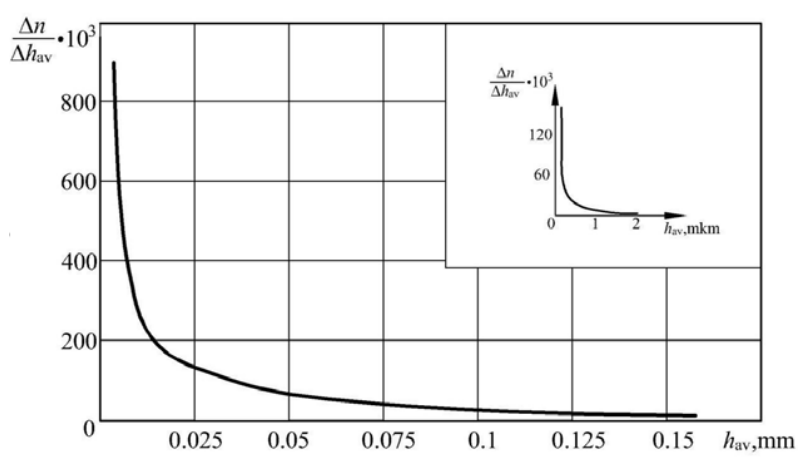

Fig. 1. The probability density distribution of the film particles on the "wheel-rail" surface

$\mathrm{X}$-ray diffraction pattern showed iron particles with a highly deformed crystal lattice, a line of compounds of iron oxide hydrate, calcium carbonate, as well as Fe, $\mathrm{Fe}_{3} \mathrm{O}_{4}$ and $\mathrm{SiO}_{2}$, herewith less than half of iron and its oxides were found.

The results of chemical analyses indicate that the main components of surface railheads' contaminations are oxides of iron and silicon. The percentage ratio between them depends on the state of ballast section and silica sand supply under the wheels of locomotives, as well as the sand brought in by the wind currents. Spectral analyses of the samples indicate the content of 6-10\% Al, Si, $\mathrm{Ca}$ and $\mathrm{Mn}, \mathrm{C}, \mathrm{S}, \mathrm{Mg}, \mathrm{Pb}, \mathrm{Ni}, \mathrm{Cu}$ in insignificant quantities. The averaged thickness of the contamination film layer in the middle of the rail head is $1 \mu \mathrm{m}$ for light and shiny surfaces, and up to $4 . .9 \mu \mathrm{m}$ for grayer ones (Table 1). Thus, from the analysis of the source [8] we can conclude that:

1. Mostly the rails are covered with colloidal contaminations with a film thickness of 1 to $20 \mu \mathrm{m}$, and 
their composition is particles of the wear of wheel and rails $(30-70 \%)$ and impurities carried by the wind currents with sand from the subgrade.

2. Small-sized solid particles that make up the bulk of wheel and rail contaminations form structured systems and have structural and rheological properties. Further studies of the rheological properties of contaminations will help to reveal the physical nature and electrical properties of the films.

Therefore, it can be assumed that iron and silicon in contaminations and under conditions of relatively powerful specific pressure on the contact surface form film crystalline structures with nonlinear semiconductor properties that provide electrical resistance of the train shunt.

The article [7] presents the results of statistical studies of $R_{\text {sh }}$ and the surface leakage coefficient $\rho$ of the track circuits, as well as the influence of the values of these criteria on the sizes of the track circuits' stability regions. It is shown that a change in the above mentioned criteria in the direction $\rho>0$ and $R_{\mathrm{sh}}<0.06$ Ohm allows significant expansion of stability region of the track circuits. For example, at $\rho=0.5$, the limiting insulation resistance in the rail line $800 \mathrm{~m}$ DC track circuit drops 1.6.. 1.8 times; if we take in the calculations $R_{\mathrm{sh}}=0.03 \mathrm{Ohm}$, then this resistance in the code track circuit with a length of $1000 \mathrm{~m}$ will decrease from 0.37 to $0.13 \mathrm{Ohm} \cdot \mathrm{km}$.

The track circuit stability is determined by the following coefficient:

$$
\varepsilon=\frac{r_{i 1}\left(R_{\mathrm{sh}}=0,06\right)}{r_{i 1}\left(R_{\mathrm{sh}}<0,06\right)},
$$

where $r_{i 1}$-is the minimum limiting insulation resistance at $R_{\mathrm{sh}}=\operatorname{var}[6]$.

Fig. 2 presents the probability distributions of the shunt resistance obtained by measuring with a microhmmeter [7].

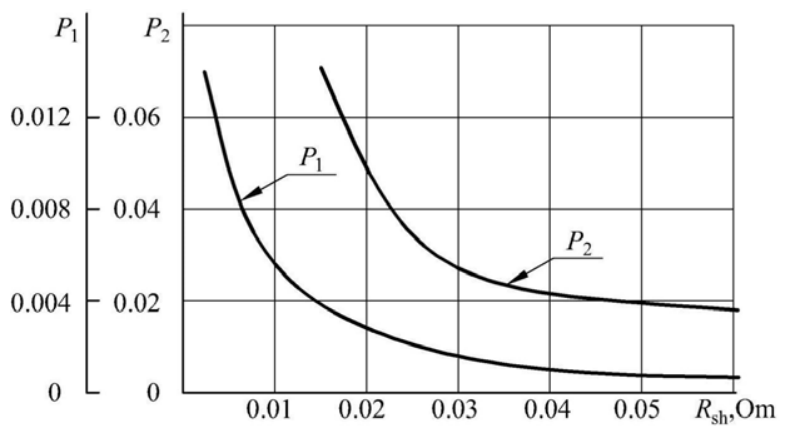

Fig. 2. The probability distribution function of shunt resistance

As one can see from Fig. 2 when reducing the shunt resistance to less than $0.03 \mathrm{Ohms}$, the probability $P\left(R_{\text {shf }}>R_{\mathrm{sh}}\right)$ sharply increases, which, apparently, from the viewpoint of signaling and interlocking systems ' security prevents the adoption of absolute values of $R_{\text {shf }}<0,03-0,04 \mathrm{Ohm}$ as the calculated ones. The authors [6, 7] admit the possibility of reducing the standard shunt (up to $0.03 \mathrm{Ohms}$ ) in automatic block systems, taking into account the resistance of two wheel sets, assuming that the location of such wheel sets at the wayside track circuit is possible only in the traffic light area.

Meanwhile, considering the calculated data of the track circuit with low insulation resistance, in our opinion, it is quite possible to calculate the track circuit using the existing normals with $R_{\mathrm{sh}}=0.03 . .0 .04 \mathrm{Ohms}$. At the same time, it is possible to estimate the real gain by reducing the limiting insulation resistance $R_{\mathrm{i} 1}$.

\section{Influence of dynamic effects on the processes of film material formation on the "wheel-rail" contact}

In the process of the train movement, a reliable electrical contact along the contact line of the wheel rim and the rail is required. Calculations of the train control schemes on the way take into account the static state of the transition resistance $R_{\text {sh }}$ between the rails no more than the standard value of $0.06 \mathrm{Ohms}$. Experience has proven that it is the dynamic effects of axial loadings over the contact resistance area of "wheel-rail" have the most significant influence on the shunt. The load transmission from the wheels to the rail occurs at a small area, which is interesting to us, the material on it is experiencing a three-dimensional stress state.

The research of stress distribution in rails by the methods of the elasticity theory $[1,2]$ showed that their values exceed the yield strength of modern rail steel. It is shown that the design and metal of the rails in the contact area of the rail and wheel can withstand higher stresses without plastic deformations.

The contact areas and contact stresses essentially depend on the contact form of the bodies: the rolling surface of the wheels (new or machined ones) has a conical shape, but during calculations the surface is considered cylindrical (Fig. 3).

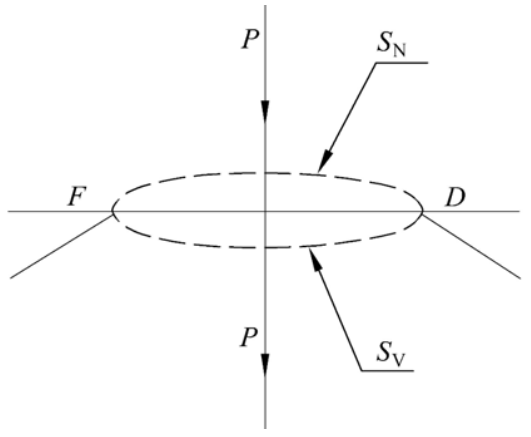

Fig. 3. Conditional nature of the elastic deformations of contacting cylinders $\mathrm{S}_{\mathrm{N}}$ and $\mathrm{S}_{\mathrm{V}}$

In this case, the pressure intensity within the contact surface is approximately distributed according to the law of the semi-ellipsoid $A x^{2}+B y^{2}=C$, where $A, B-$ depend on the radius of bodies ' curvature, and $C$ is the value of bodies` convergence due to elastic deformation. 
The dependence of the force on the stress $\sigma_{\max }$ is determined by the following formula:

$$
P=\sigma_{\max } \cdot \frac{2}{3} \cdot \pi \cdot a \cdot b
$$

where $P$ is the load, kg; $a, b$ - ellipse semi-axes, $\mathrm{cm}$.

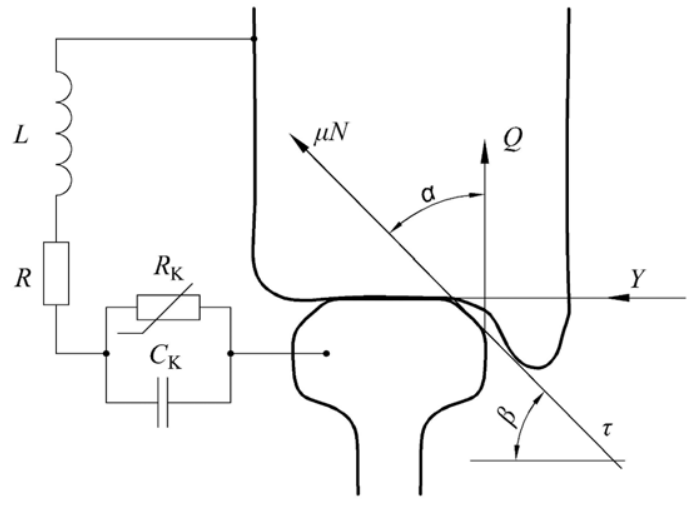

Fig. 4. The distribution of forces acting on the "wheelrail" contact

The volume of the stress semi-ellipsoid [1]:

$$
V=\frac{2}{3} \cdot \pi \cdot a \cdot b \cdot l
$$

where $\frac{A}{B}=\frac{R_{1}}{R_{2}}$ is the ratio proportional to the semi-axes $a$ and $b: A=\frac{1}{2 \cdot R_{2}}, B=\frac{1}{2 \cdot R_{1}}, l$ is the length of the contact surface area.

From this we can find that

$$
\sigma_{\max }=\alpha \cdot \sqrt[3]{\frac{P \cdot E^{2}}{R^{2}}}
$$

where $\alpha$ is a coefficient depending on the ratio $\frac{A}{B}=\frac{r}{R}$, $E$ is the elasticity modulus of the rail steel.

The values of $r$ and $R$ represent a smaller and larger radius of curvature. It is considered that at $\sigma_{\max }-\mathrm{a}$ dangerous point of stress, which lies at a depth below the area $\left.\sigma_{\text {calc }}=0,6 \sigma_{\max }\right)$, in the center of the ellipse $\sigma_{\mathrm{c}}=n_{1} \sigma_{\max }$ along the major semi-axis $\sigma_{s}=n_{2} \sigma_{\max }$, where the coefficients $n_{1}$ and $n_{2}$ are given in the works $[1,3]$.

The bogie in the process of hunting in the track curve rests upon the support line with the wheel flange of the first set and the rear one moves with a clearance $25 . .30$ $\mathrm{mm}$ "rail track - flange". Herewith the friction force $F_{\text {tr }}=\mu \cdot \theta$, arises, where $\mu=0,25$ is the coefficient of friction, and $\theta$ is the gross weight which puts the pressure on the axis. It follows that the action forces of the bogie weight $P_{\mathrm{b}}$ on the support and internal rails become different in value (up to $6-7 \%$ from $0.5 P_{\mathrm{b}}$ ). This changes the "wheel-rail" contact area of the bogie. The values of loadings and unloadings of the wheels are estimated by a dynamic factor:

$$
K_{\mathrm{d}}=\frac{P_{\mathrm{b}}}{P_{\mathrm{st}}-q},
$$

where $P_{\mathrm{st}}$ is a steady load on the axle, $q$ is direct weight (pressure) of the wheel.

According to estimations of the works [1, 3], the factor $K_{\mathrm{d}}$ varies depending on the speed of movement in the range from 0.28 to 0.66 at the speeds of $60-120 \mathrm{~km} / \mathrm{h}$. It should be borne in mind that $K_{\mathrm{d}}$ is the result of various body oscillations during rolling, pitching and jumping. The change in the value of $K_{\mathrm{d}}$ under these effects may be in the range of $30-50 \%$. It was found that the oscillation period of the wheel-rail pair reaches 35-45 ms.

As the rails wear out, the rolling surfaces of the rail head change, their radii increase from 300 to $320 \mathrm{~mm}$. The actual increase in the radius of the rail head curvature leads to an increase in the rolling surface:

$$
R_{\mathrm{a}}=\frac{m}{m-1} \cdot R_{\mathrm{c}}
$$

where $m=\frac{R_{\mathrm{c}}}{R}$, and $R_{\mathrm{c}}$ is the radius of curvature forming the rolling surface.

Herewith, in the track curves, the steering wheel contact with the outer rail occurs along smaller radii of curvature, which causes an increase in stresses and deformations in the outer rails [2, 3] (Fig. 5).

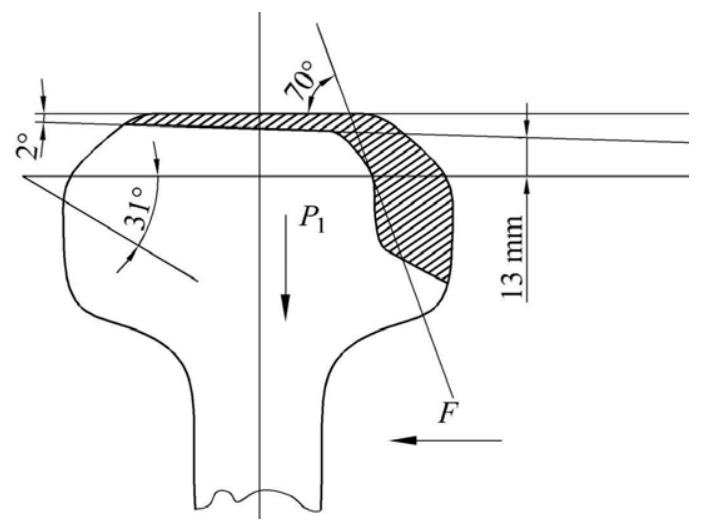

Fig. 5. Cross-section of the wheel in the curve of $368 \mathrm{~m}$ after passing 104 million tons of cargo

The wear intensity of rails $[2,3]$ mainly depends on the radius of the track curvature $R_{\text {cur }}$. Thus, with $R_{\text {cur }} \leq 400 \mathrm{~m}$, lateral wear occurs 2.5 times faster than in the sections where $R_{\text {cur }} \leq 600 \mathrm{~m}$. With significant side wear the wheels with their flanges start rolling on the galling foundation of the lateral edge of the rail. If the force $P_{1}$ pressing the wheel down, will be greater than the force $P_{2}(F)$, which impedes it, then the classic scheme of negotiating of the bogie's first wheel will be observed when the flanges climb onto the outer rail and the wheels do not derail under the action of the horizontal force $F$. It can be seen that when the rail is worn, the area $S_{\mathrm{c}}$ of the "wheel-rail" contact increases 
(by 15-20\%) and in the curved track sections it may exceed the values obtained below.

For example, we give the calculation of the contact stresses in the rails and the evaluation of the "wheel-rail" rolling surface. If we calculate the dynamic wheel loading on the rail [12] with the axial loading of a fouraxle heavy car 10.2 tons, the movement speed $85 \mathrm{~km} / \mathrm{h}$, the rail type P50, we obtain the following:

$$
\theta_{\mathrm{dyn}}=\frac{P}{g}=18669 \mathrm{~kg}
$$

The wheel radius is $R=47.5 \mathrm{~cm}$, the radius of the rolling surface is $r=30 \mathrm{~cm}$. Hence, $\frac{A}{B}=\frac{r}{R}=0,632[2$, Table. 33], $\alpha=0.459$. Then from the formula (see above)

$$
\sigma_{\max }=0.459 \cdot \sqrt[3]{\frac{18669 \cdot\left(2.1 \cdot 10^{6}\right)^{2}}{47.5^{2}}}=15200 \mathrm{~kg} / \mathrm{cm}^{2}
$$

The coefficients $n_{1}=0.23 ; n_{2}=0.241$, then the stresses in the directions of the rolling area axes will be: $\sigma_{\text {tc }}=0.23 \cdot 15200=3500 \mathrm{~kg} / \mathrm{cm}^{2}$,

$\sigma_{\text {ext }}=0.241 \cdot 15200=3620 \mathrm{~kg} / \mathrm{cm}^{2}$, being at the yield strength limit.

Estimation of the rolling area: $S_{\text {era } 2}=\frac{P}{\sigma_{\max }}=\frac{18700}{15200}=1.23 \mathrm{~cm}^{2}$, in the danger area, with stress $\sigma_{\mathrm{tc}}$ obtained $S=\frac{18700}{3620}=5.17 \mathrm{~cm}^{2}$.

To determine the fictitious radius of the rail head with the wear of rolling surface $3-4 \mathrm{~mm}$, the axle loading 10.2 tons, the radius of curvature $R_{\mathrm{c}}=170 \mathrm{~mm}$, and the radius $r=80 \mathrm{~mm}$, we will find:

$$
m=\frac{170}{80}=2.1 ; R_{\mathrm{a}}=\frac{2.1}{1.1} \cdot 8=15.3 \mathrm{~cm}
$$

Then $\frac{A}{B}=\frac{15.3}{47.5}=0.322, \alpha=0.586$;

$\sigma_{\max }=0.586 \cdot \sqrt[3]{\frac{18700 \cdot\left(2.1 \cdot 10^{6}\right)^{2}}{47.5^{2}}}=19400 \mathrm{~kg} / \mathrm{cm}^{2}$.

From [3] $n_{1}=0.22 ; n_{2}=0.23$. Therefore: $\sigma_{\mathrm{tc}}=5240$ $\mathrm{kg} / \mathrm{cm}^{2} ; \quad \sigma_{\text {ext }}=4460 \quad \mathrm{~kg} / \mathrm{cm}^{2}, \quad$ and $\sigma_{\text {calc }}=0,6 \cdot \sigma_{\max }=11640 \mathrm{~kg} / \mathrm{cm}^{2} \mathrm{~kg} / \mathrm{cm}^{2}$.

$$
\text { Hence, } \quad S_{\mathrm{K}}=\frac{19400}{4460 \ldots .5240}=4,34 \ldots 3,7, \quad \text { and }
$$

approximately it turns out that the surface area of the "wheel-rail" contact can be expected in the range $1.23 . .4 .34 \mathrm{~cm}^{2}$.

\section{Redistribution of efforts on the contact areas "wheel-rail"}

The rail head metal in the process of wheel hunting or when moving in the curved track sections works in the mode of compression or sliding; at the same time a side jolt is observed, in which the forces of the areas contact are established on the inner and opposite rail as $P_{1}=P_{0}+\Delta P$ and $P_{2}=P_{0}-\Delta P$, respectively. It is established that the pressure difference is $\Delta P=2.25-3.75$, and the difference of stresses is greater than $15 \cdot 10^{3} \mathrm{~kg} / \mathrm{cm}^{2}$.

As the rolling surface [1] wears out instead of the conicity generator line (Fig. 1) at the end of the junction plane to the flange "throat" the changes in the rolling sliding surfaces appear, where $S_{\mathrm{K}}=S_{\mathrm{K}}^{*}+S_{\mathrm{sr}}$, , where $S_{\mathrm{K}}^{*}$ - is the rolling surface, $S_{\mathrm{sr}}$ is the sliding surface of the flange along the lateral edge of the rail head.

The sliding condition of the wheel flange is assessed by the Nadal criterion [3]:

$$
\frac{Y}{Q}<\frac{\tan \beta-\mu}{1+\mu \cdot \tan \beta} \leq 1,
$$

setting the ratio of the forces acting on the wheel: $\mathrm{Y}$ force, pushing the wheel up, Q - force pressing on the wheel down, keeping it inside the track. Y and Q create possible flange wear, which threatens to strike along the switch point's end, if the gap "switch point - stock rail" is more than $4 \mathrm{~mm}$.

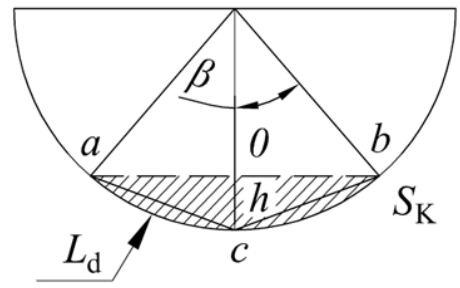

Fig. 6. Sliding area "wheel flange-lateral edge of the rail"

Suppose that the length of the generator line of sliding surface has a radius $\mathrm{R}=25 \mathrm{~cm}$, and the slide angle is determined from the Nadal condition, then it is possible to determine the sliding area of a flange from $a b c$ sector triangle (Fig. 6), or by the ellipse (segment) formulas.

If we assume that due to the flange wear, the slide angle exceeds $100 \%$, then the sliding area $S_{\mathrm{K}}$ can reach the values of $2 \mathrm{~cm}^{2}$ and higher. However, these values of the area are approximate and require experimental verification. It should be noted that the train shunt resistance, on average, is relatively stable during the dynamic "wheel-rail" interaction when moving in a straight line, when the influence of the bogie wheel is observed, or in the curve and flange sliding along the lateral edge of one rail head.

\section{Electrical equivalent circuit of film and estimation of parameters of its elements}

Fig. 4, a variant of the equivalent circuit (EC) of the make-before-break contact is considered - the film material and the ferromagnetic "wheel - rail" material conjugated with it on both sides. The circuit contains 
linear elements: wheel inductance $L$, wheel resistance $R=R_{\mathrm{K}}+2 \cdot R_{\mu}$, presumably active resistance of ferromagnetic layers (substrate) $-\Delta R_{\mu}$ and film capacitance $C_{\mathrm{K}}$, as well as a nonlinear element - active resistance $R\left(P_{\mathrm{K}}, S_{\mathrm{K}}, U\right)$, which is a function mainly of pressure, film area and stress. Moreover, the film mainly consists of iron oxide $\mathrm{Fe}_{2} \mathrm{O}_{3}$, sand and red dust stuck to the rail.

Above is an estimation of the geometric parameters of the film, and below - the order of values of the electrical elements of the EC.

The impedance of the equivalent circuit is expressed as:

$$
Z=j \omega L+\frac{R \cdot \frac{1}{j \omega C}}{R+\frac{1}{j \omega C}}=\frac{j \omega L-R C L \omega^{2}}{1+j \omega R C}
$$
obtain:

Following [4] after transformations (4) we will

$$
Z=\frac{j \omega L-R C L \omega^{2}+R}{(1+j \omega R C)} \cdot \frac{(1-j \omega R C)}{(1-j \omega R C)}
$$

And finally, we get resistance in a complex form:

$$
Z=\frac{R+j \cdot\left(\omega L-\omega^{2} R^{2} C+\omega^{3} R^{2} C^{2} L\right)}{1+\omega^{2} R^{2} C^{2}}
$$

Which makes it possible to determine the resistance modulus of the train shunt:

$$
|Z|=\frac{\sqrt{R+\left(\omega L-\omega^{2} R^{2} C+\omega^{3} R^{2} C^{2} L\right)}}{1+\omega^{2} R^{2} C^{2}}
$$

The electrical resistance of the film formed during the motion, as a rule, is not destructible, but it can be broken down [5]. With a relatively long contact time, socalled coherent effect appears - with increasing speed of movement the film does not have time to be broken down, but the joint resistance remains relatively high. Such a state can more often occur when moving the cars of light-weight electric trains.

Capacitance $C$ depends only on the form of the dielectrics material and can be approximately compared with the capacitance of the area at the transition of the tread-rail, whose area reaches $5 \mathrm{~cm}^{2}$.

Capacitance is determined by the formula:

$$
C=\frac{\varepsilon \cdot S}{l}
$$

Insulation thickness of $h=7.4 \mu \mathrm{m}$, average dielectric constant for insulating material $\varepsilon=8$, then the capacitance: $C=\frac{8 \cdot 5,1 \cdot 10^{-4}}{7,4 \cdot 10^{-3}}=5,4 \cdot 10^{-4} \mu \mathrm{F}$.

If we assume that the film resistance (approximately, as in silicon diodes) is $0.5 \mathrm{Ohm}$, then the denominator of resistance according to the formula (15) at a frequency of $10 \cdot 10^{-3} \mathrm{~Hz}$ is approximately equal to one, and the modulus

$$
\begin{gathered}
|Z|=\sqrt{R^{2}+\left(\omega L+\omega^{2} R^{2} C+\omega^{3} R^{2} C^{2}\right)} \approx \\
\approx R=7 \cdot 10^{-4} . .0 .5
\end{gathered}
$$

i.e. the modulus is approximately equal to the active resistance of the "wheel-rail" contact in the range from $10^{-4}$ to $0.5 \mathrm{Ohms}$ (in the presence of films).

Calculating the derivation (with respect to the argument $\omega$ ) of the resistance $Z$, and equating it to zero, we obtain the biquadratic equation for $\omega$ :

$$
3 R L C \omega^{4}+4 R^{2} L C^{2} \alpha \omega^{2}+\alpha^{2}=0
$$

where $\alpha=L-C R^{2}$

If $\alpha<0$ or $L<C R^{2}$, then the real roots (18):

$$
\omega^{2}=\frac{-2 \alpha \pm \alpha}{3 R^{2} L C^{2}}>0
$$

From equation (18), the value of EC inductance (Fig. 2) is obtained, $L=0,12 \cdot 10^{-7} \mathrm{H}$ or $1.2 \mu \mathrm{H}$

Equation (18) makes it possible to use the resistance law $Z$ at different signal frequencies, resistance variations $R$ and its effect on the shunt resistance, etc.

In conclusion, it can be noted that with low contact resistance of the "wheel-rail" contact and the corresponding values of $R, C$ and $L>C R^{2}$ (19) is a practically increasing linear dependence on frequency. With bad contacts, when $L<C R^{2}$, the dependency $Z(\omega)$ decreases. The dependencies with large transition resistances of the contact are of the greatest interest. In such conditions at the stations it is more profitable to use overfrequencies of the tonal spectrum (up to $3 \mathrm{kHz}$ ). This will make it possible to improve the double rail plan of the station using shorter track circuits and achieve the reduction in the insulating joints.

An overview of the problem state of rail circuits' shunting and the obtained approximate values of the electrical parameters of the EC affecting the shunt mode make it possible to better understand the physical nature of the dynamics of electrical and mechanical interactions when solving the "wheel-rail" contact problem and recognize as appropriate more detailed studies of such an urgent problem of signaling and interlocking devices.

It is of interest (Fig. 1, 2) external qualitative similarities in the nature of the probability distributions of shunt resistances and the sizes of contamination particles. It can be argued that both physical random processes - the film formation on rails and the value of its electrical resistance are dependent and correlated with each other.

Let us turn to the analytical proof of such a statement. 


\section{The correlation dependency estimation of the parameters of the film and train shunt}

Let us consider the research results of interrelated problems $[7,8]$. In one of them [8], as noted above, the effects of contamination of the friction surfaces of rails and wheels and the estimation of their influence on the friction coefficient $(0.1-0.45)$, as well as the tractive characteristics of locomotives, were investigated.

According to the results of processing statistical material [8], the following functions are presented: the function $f\left(h_{\mathrm{av}}\right)=\frac{\Delta n}{\Delta h_{\mathrm{av}}} \cdot 10^{3}$ of probability density of the average film thickness on the rolling surface of rails and the function $F\left(h_{\mathrm{av}}\right)$ of this random variable distribution (Fig. 7).

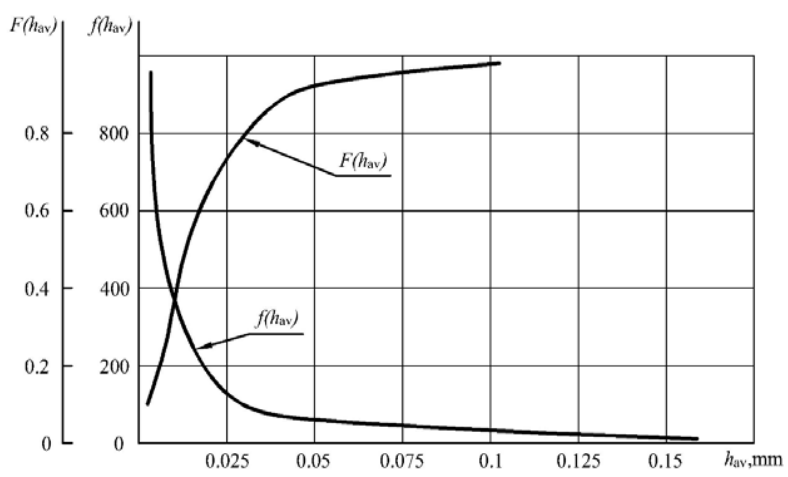

Fig. 7. Function graphs $\mathrm{f}\left(\mathrm{h}_{\mathrm{av}}\right)$ and $\mathrm{F}\left(\mathrm{h}_{\mathrm{av}}\right)$

The construction of the function $F\left(h_{\mathrm{av}}\right)$ is performed in the following sequence.

From the experimental density function, the number of contamination particles in each discharge was determined (from 0 to 4000). In case of equality $\frac{\Delta n_{\mathrm{i}}}{\Delta h_{\mathrm{av}}} \cdot 10^{3}=800$, where $n_{\mathrm{i}}$ is the number of particles hitting to discharge $\Delta h_{\text {av }}=4,5 \mathrm{~mm}$ (Fig. 7), the value $n_{1}=800 \cdot 4,5=3600$, is determined, similarly for $n_{2}=600 \cdot 4,8=2880$, etc. The total sample size for the number of hits in the range from 0 to 800 was $N=$ 18900. Hence, the frequencies of hits in each discharge were determined: $\quad p_{1}=\frac{3600}{18900}=0,1905$, $p_{2}=\frac{2880}{18900}=0,1524$, etc.

According to the results of calculations, the probability distribution function of the particles from the value of the average film diameter was constructed [8] (Table 2).

Table 2. Frequencies and particle sizes by discharges

\begin{tabular}{|c|c|c|c|c|c|}
\hline$F\left(h_{\mathrm{av}}\right)$ & 0.98 & 0.69 & 0.45 & 0.34 & 0.19 \\
\hline$h_{\mathrm{av}} \cdot 10^{-3}, \mathrm{~mm}$ & 56.0 & 18.0 & 8.2 & 4.8 & 3.25 \\
\hline
\end{tabular}

From Figure 7 it follows that for the approximation of the function $f\left(h_{\mathrm{av}}\right)$ the exponential distribution law can be applied.

Experimental studies of the train shunts resistance [7] were carried out in two specially equipped track circuits with a length of $12.5 \mathrm{~m}$, located on the track sections with autonomous traction. According to the proposed method, the probability that a signal exceeds a given resistance level $R_{\mathrm{sh}}$ is measured by the formula $P_{R_{\mathrm{sh}}}=\frac{t_{\mathrm{i}}}{T}$ where $t_{\mathrm{i}}$ is the total duration of exceeding the $i$-th level over the observation period $T=8760 \mathrm{~h}$. Based on the statistical materials, the distribution functions of the random variable $F\left(R_{\mathrm{sh}}\right)$ and the probability density $f\left(R_{\mathrm{sh}}\right)$ of resistance $R_{\mathrm{sh}}$ (Fig. 8) were additionally constructed with estimations of the random variable up to $5 \cdot 10^{-3} \mathrm{Ohms}$ (with data less than this estimation, the lines were broken).

When statistics were obtained to the left of the $0.0075 \mathrm{Ohm}$ resistance, the density function could be approximated by the Rayleigh distribution law:

$$
f\left(R_{\mathrm{sh}}\right)=\frac{R_{\mathrm{sh}}}{\sigma^{2}} \cdot \exp \left(-\frac{R_{\mathrm{sh}}^{2}}{2 \cdot \sigma^{2}}\right), R_{\mathrm{sh}} \geq 0, \sigma>0
$$

where $R_{\mathrm{sh}}$ depends on the mathematical expectation $M\left(R_{\mathrm{sh}}\right)$.

The descending part of the probability density function more than $(5-10) \cdot 10^{-3} \mathrm{Ohm}$ is reliably described by the exponential distribution

$$
f\left(R_{\mathrm{sh}}\right)=\lambda \cdot \exp \left(-\lambda \cdot R_{\mathrm{sh}}\right)
$$

where the parameter $\lambda=\frac{1}{m_{R_{\mathrm{sh}}}}=45,41 / \mathrm{Ohms}$.

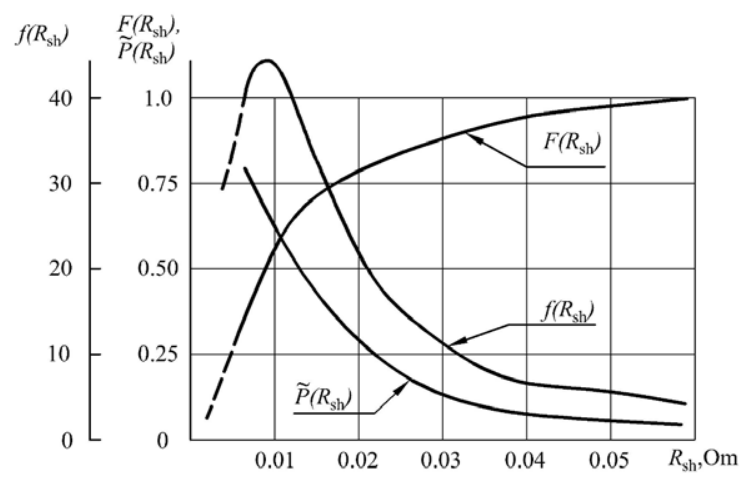

Fig. 8. Graphs of distribution functions $F\left(R_{\mathrm{sh}}\right)$, probability density $f\left(R_{\text {sh }}\right)$ and dependencies $P\left(R_{\text {sh }}\right)$

Table 3 shows the probabilities of the distribution function of the train shunt resistance and film thickness [7]

Table 3. Probabilities of the distribution function

\begin{tabular}{|c|c|c|c|c|c|}
\hline$F(x)$ & 0.2 & 0.4 & 0.6 & 0.8 & 1.0 \\
\hline$R_{\mathrm{sh}} \cdot 10^{-3}, \mathrm{Ohm}$ & 5.12 & 7.9 & 16.5 & 32.15 & - \\
\hline$h_{\mathrm{av}} \cdot 10^{-3}, \mathrm{~mm}$ & 3.0 & 8.2 & 18.1 & 30.0 & - \\
\hline
\end{tabular}


The authors of work [7] claim that:

1. Due to the increase in the probabilities $P\left(R_{\mathrm{sh}}>0.06 \mathrm{Ohm}\right)$, according to the conditions for increasing the track circuit's operational performance, a significant decrease in the standard value $R_{\mathrm{sh}}$ cannot be achieved.

2. The changes dynamics of the function $\tilde{P}\left(R_{\mathrm{sh}}\right)$ (Fig. 8) shows that for automatic block systems operating with a reduced insulation resistance of the rail line, the train shunt resistance of two axles of wheel sets equal to $0.03 \mathrm{Ohm}$ can be assumed as a normative value. On the one hand, the probability $P\left(R_{\mathrm{sh}}=0.03 \mathrm{Ohms}\right)$ relative to $0.06 \mathrm{Ohms}$ does not increase so much, on the other hand, the use of calculations with a shunt resistance of $0.03 \mathrm{Ohms}$ at a critical point of the shunt location - near intermediate block signal - does not pose a safety hazard because the movement is carried out on the restrictive signal.

Fig. 8 shows that over $85 \%$ of the wheels pass along the rails at $R_{\mathrm{sh}}<0.02 \mathrm{Ohm}$.

Note that by reducing the normative value of the train shunt resistance to $0.03 . .0 .04 \mathrm{Ohms}$, the performance area of rail circuits' operating modes is expanded, mainly due to increase in the power supply voltage and, as a result, a reduction in the limiting insulation resistance $R_{\mathrm{il}}$ of the rail line.

The analysis of the physico-chemical nature of the film material and the obtained stochastic dependencies of random variables (Fig. 7, 8, [7, 8]) - the geometrical dimensions of the film covering the rolling surface "wheel-rail" and the electrical resistance of the train shunt - indicate that the film characteristics influence the value of $R_{\mathrm{sh}}$.

The film parameters at the "wheel-rail" contact not only affect the friction coefficient and the locomotives" traction characteristics, but also make the main contribution to the formation of the electrical resistance modulus of the train shunt and, as a consequence, the performance criteria for rail circuits and the safety of signaling and interlocking systems.

To quantify the dependency intensity of $y$ - the train shunt resistance on the $x$ - the film parameters, let us turn to a mathematical model that studies such dependencies [9]. We consider in the first approximation that there is a linear correlation relationship between the random variables $x\left(h_{\mathrm{av}}, \mathrm{mm}\right)$ and $y\left(R_{\mathrm{sh}}, \mathrm{Ohm}\right)$. This means that the mathematical expectation $y$ is linearly dependent on the value $x$. The dependency graph (the regression line $y$ on $x$ ) has the equation $M(y)=\rho \cdot x+b$, where $\rho$ and $b$ are some unknown constants. The value of the correlation coefficient $r_{\mathrm{xy}}$ is also unknown.

The results of independent observations $[7,8]$ over the values of $\mathrm{x}$ and $\mathrm{y}$, obtained in pairs on the same probabilistic space of their appearance, are presented in Figures 7 and 8, as well as in Table 3 . From these sources, the necessary information to search for $\rho, b$ and $r_{x y}$ estimations was obtained. The values of these estimations correspond to the minimum of the function
$F(\rho, b)=\sum_{\mathrm{k}=1}^{\mathrm{n}}\left(\rho \cdot x_{\mathrm{k}}+b-y_{\mathrm{k}}\right)$ and the equation systems for partial derivatives $\frac{\partial F}{\partial \rho}$ and $\frac{\partial F}{\partial b}$, are obtained, as required by the extremum conditions and the method of least squares:

$$
\begin{gathered}
\rho=\frac{n \cdot \sum_{\mathrm{k}=1}^{\mathrm{n}} x \cdot y_{\mathrm{k}}-\sum_{\mathrm{k}=1}^{\mathrm{n}} x_{\mathrm{k}} \cdot \sum_{\mathrm{k}=1}^{\mathrm{n}} y_{\mathrm{k}}}{n \cdot \sum_{\mathrm{k}=1}^{\mathrm{n}} x_{\mathrm{k}}{ }^{2}-\left(\sum_{\mathrm{k}=1}^{\mathrm{n}} x_{\mathrm{k}}\right)^{2}} \\
b=\frac{n \cdot \sum_{\mathrm{k}=1}^{\mathrm{n}} x_{\mathrm{k}}^{2} \cdot \sum_{\mathrm{k}=1}^{\mathrm{n}} y_{\mathrm{k}}-\sum_{\mathrm{k}=1}^{\mathrm{n}} x_{\mathrm{k}} \cdot \sum_{\mathrm{k}=1}^{\mathrm{n}} x_{\mathrm{k}} \cdot y_{\mathrm{k}}}{n \cdot \sum_{\mathrm{k}=1}^{\mathrm{n}} x_{\mathrm{k}}{ }^{2}-\left(\sum_{\mathrm{k}=1}^{\mathrm{n}} x_{\mathrm{k}}\right)^{2}}
\end{gathered}
$$

To estimate the correlation coefficient, let us use the relation

$$
r_{\mathrm{xy}}=\rho \cdot \frac{\partial x}{\partial y},
$$

where $\sigma_{\mathrm{x}}$ and $\sigma_{\mathrm{y}}$ are the mean square deviation of $x$ and $y$, respectively.

The values of the point estimations for the distribution parameters of the mean square deviations $\sigma_{\mathrm{x}}$ and $\sigma_{\mathrm{y}}$ the mathematical expectations $m_{\mathrm{x}}$ and $m_{\mathrm{y}}$ of the film's geometric dimensions and the train shunt resistance, obtained from statistical observations, are presented in Table $4[7,8]$ and are used below to calculate the correlation coefficient and the regression line.

Table 4. The values of the point estimations

\begin{tabular}{|c|c|c|}
\hline Parameter & $\begin{array}{c}\text { Mathematical } \\
\text { expectation }\end{array}$ & $\begin{array}{c}\text { Mean square } \\
\text { deviations }\end{array}$ \\
\hline$x$ & $11.6 \cdot 10^{-3} \mathrm{~mm}$ & $21.7 \cdot 10^{-3} \mathrm{~mm}$ \\
\hline$y$ & $22.0 \cdot 10^{-3} \mathrm{Ohm}$ & $41.0 \cdot 10^{-3} \mathrm{Ohm}$ \\
\hline
\end{tabular}

By substituting the variables in expressions (3-5), we obtained the values of the parameters $\rho=-1.61, b=0.025$ and the correlation coefficient $r_{\mathrm{xy}}=0.82$. The obtained value of $r_{x y}$ indicates a fairly close relationship between the train shunt resistance and the film thickness of contaminations formed on the rolling surface of the wheel on the rails.

The volume of statistical data obtained during the research: 18900 in [7] and 2050000 in [8] is sufficient to correctly calculate the maximum likelihood estimations for the parameters of the distributions taken here and to estimate the correlation coefficient.

The linear regression equation for $y$ on $x$ has the following form: $M(y)=-1,61 \cdot x+0,025$. Calculations by this equation are performed on the average measured values of the parameter $x$. 


\section{Conclusions}

1. Using the calculations of the dynamic interaction of wheels of rolling stock and rails we obtained the area of the "wheel-rail" rolling surface, taking into account the different conditions of the dynamics of interaction and wear of rails and wheel elements.

2. It is shown that reducing the normative value of the train shunt resistance to $0.03 . .0 .04 \mathrm{Ohms}$ is advisable for signaling and interlocking systems, especially for the railway sections with a reduced resistance of rail line insulation.

3. It has been established that train wheel sets moving on a track circuit, in more than $85 \%$ of cases, provide a train shunt resistance of less than 0.02 Ohms.

4. An approximate estimation of the geometrical parameters of the film formed on the "wheel-rail" rolling surface was obtained; more complete electrical equivalent circuit of the train shunt circuit has been proposed, which allows analyzing the influence of the parameter values of the circuit elements and the signal current frequency, in particular, on the train shunt resistance modulus.

5. It was proposed a method for calculating the correlation dependence of the train shunt resistance from the film parameters on the "wheel-rail" rolling surface, which made it possible to obtain a quantitative estimation of the correlation coefficient $\left(r_{\mathrm{xy}}=0.82\right)$, indicating a close relationship between dynamic and physico-chemical formation processes of film material characteristics and train shunt resistance.

\section{References}

1. A.Ja. Kogan. Dinamika puti i ego vzaimodejstvie $s$ podvizhnym sostavom - M.: Transport 326 s. (1997) [in Russian]
2. G.M. Shahunjac Zheleznodorozhnyj put', 3-e izd., pererab. i dop. - M.: Transport, 479 s. (1987) [in Russian]

3. M. A. Chernyshev. Prakticheskie metody rascheta puti. - M.: Transport, 226 s. (1967) [in Russian]

4. Walter J. Au problème du choix de la fréquence de courant alimentant le circuit de voie Revue Generale des Chemins defer. \# 6. - P. 22-25 (1986)

5. Hirosi Okumura. The resistance of the train shunt in the track circuits Quarterly Report of the Railway Technical Research Institute Japan National Railway. V. 3, N. 3 (1962)

6. A.P. Razgonov. $O$ nadezhnosti rel'sovyh cepej Avtomatika, telemehanika i svjaz'. \# 3. - S. 36-39 (1986) [in Russian]

7. V.A. Minin, V.S. Dmitriev, V.S. Luchinin. Ocenka znachenij kojefficienta poverhnostnoj utechki rel'sovyh cepej $i$ soprotivlenija poezdnogo shunta Vestnik VNIIZhT. \# 2. - S. 52-54 (1986) [in Russian]

8. Ju. M. Luzhnov, M. V. Rusakova, R. G. Cherepashenec. Zagrjaznenija poverhnostej katanija trenija rel'sov i koles podvizhnogo sostava Vestnik VNIIZhT. \# 4. - S. 38-41 (1972) [in Russian]

9. I.M. Petrushko, V. I. Afanas'ev i dr. Kurs vysshej matematiki-M.: Izdatel'stvo MJeI. 304 s. (2004) [in Russian]

10. Ju.A. Kravcov, B.M. Stepenskij. Verojatnostnaja model' poezdnogo shunta dlja legkih podvizhnyh edinic $i$ otcepov Trudy UJeMIIT. - Sverdlovsk.: UJeMIIT, vyp. 64. - S. 58-60 (1980) [in Russian]

11. R. Hol'm. Jelektricheskie kontakty. - M.: Inostrannaja literatura. $410 \mathrm{~s}$ (1961) [in Russian]

12. DSTU 7571:2014: Ruhomij sklad zaliznic'. Normi dopustimogo vplivu na zaliznichnu koliju shirinoju 1520 mm (2014) [in Russian] 